DOI 10.37882/2500-3682.2021.12.25

\title{
СОЦИАЛЬНЫЙ ИНТЕЛЛЕКТ КАК ПРЕДИКТОР ЛИЧНОСТНОЙ БЕЗОПАСНОСТИ ПОДРОСТКОВ С УМСТВЕННОЙ ОТСТАЛОСТЬЮ
}

\section{SOCIAL INTELLIGENCE AS A PREDICTOR OF PERSONAL SAFETY OF ADOLESCENTS WITH MENTAL RETARDATION}

\section{N. Stepanova \\ D. Maksimova}

Summary: The article considers the problem of the interdependence of the degree of personal security and the level of development of social intelligence in adolescents with mental retardation (intellectual disabilities). Special attention is paid to the consideration of the structural components of social intelligence and the levels of its development. The empirical results of this study are proposed, on the basis of which the technologies of correctional and developmental work aimed at the development of social intelligence in order to improve the personal safety of children of this category are selected.

Keywords: social intelligence, personal security, adolescence, mental retardation, social adaptation.
Степанова Наталия Анатольевна

К.псх.н., доцент, Тульский государственный педагогический университет им. Л.Н. Толстого stepanova_na@inbox.ru

Максимова Дарья Алексеевна Тульский государственный педагогический университет им. Л.Н. Толстого darmaximova@mail.ru

Аннотация: В статье рассмотрена проблема взаимообусловленности степени личностной безопасности и уровня развития социального интеллекта у подростков с умственной отсталостью (интеллектуальными нарушениями). Особое внимание уделяется рассмотрению структурных компонентов социального интеллекта и уровней его развития. Предлагаются эмпирические результаты данного исследования, на основе которых подобраны технологии коррекционно-развивающей работы, направленной на развитие социального интеллекта в целях повышения личностной безопасности детей данной категории.

Ключевые слова: социальный интеллект, личностная безопасность, подростковый возраст, умственная отсталость, социальная адаптация.

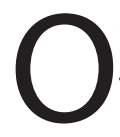
беспечение личностной безопасности сегодня является значимой проблемой, особенно если это касается лиц с ограниченными возможностями здоровья. По мнению Демьяненок Т.В., базовым показателем защиты личности можно рассматривать уровень развития социального интеллекта, включающий навык распознавать враждебное либо дружеское отношение окружающих, осмыслять ситуацию в процессе общения и предугадывать ее вероятное развитие. Этот показатель также определяет самостоятельность, социальную грамотность, качество жизни, навыки самообслуживания, способность просить помощь при необходимости, умение ориентироваться за пределами своего дома и т.д. [3].

Развитый социальный интеллект играет крайне важную роль для лиц с интеллектуальной недостаточностью, т.к. без оценки перечисленных качеств невозможно судить о наличии у них ресурсов для социальной адаптации. Уровень развития социального интеллекта позволяет нам понять, насколько отстающие в развитии лица приняты обществом, а также оценить качество их собственной жизни [6].

Необходимо отметить, что актуальность проблемы логически вытекает из особой ценности коммуникативных способностей и их проявлений для подростков, так как качество общения в данном возрасте имеет принци- пиальное значение для обеспечения личностной безопасности. Более того, развивать социальный интеллект необходимо у детей с ограниченными возможностями здоровья, общение которых имеет определенные ограничения в силу имеющегося дефекта [10].

Следовательно, при наличии нарушения развития поставленный вопрос представляет еще больший интерес, поскольку подразумевает возможность изучения характерных особенностей коммуникации подростков с интеллектуальной недостаточностью и их влияние на личностную безопасность.

Наше исследование строится на предположении о том, что степень личностной безопасности напрямую связана с уровнем развития социального интеллекта.

В качестве основных структурных элементов социального интеллекта Баширов И.Ф. представляет когнитивный, эмоциональный и коммуникативно-организационный (поведенческий) компоненты:

1. когнитивный компонент отвечает за адекватное распознавание, анализ и предвидение развития ситуации взаимодействия с учётом изменяющегося контекста;

2. эмоциональный обеспечивает эмоциональное проникновение в личностный и социально-психологический контекст ситуации взаимодействия; 
3. благодаря поведенческому компоненту происходит актуализация внутреннего психологического ресурса для адекватного решения коммуникативных задач [1].

По мнению большинства исследователей, основными компонентами психологической безопасности, выступают состояния целостности и защищенности. В то же время, нарушение целостности личности, проявляющееся в диссоциации ощущений, аффекта, фрагментации личности и потери связей между ее отдельными сторонами, усилении внутренних конфликтов, а также нарушение защищенности, которое выражается в различных искажениях психологических границ личности, свидетельствуют о потере чувства психологической безопасности.

Итак, трем компонентам социального интеллекта соответствуют два компонента личностной безопасности. Эмоциональный (социальные качества) и когнитивный (самооценка и уровень притязаний) компоненты социального интеллекта отвечают за такой компонент личностной безопасности, как целостность. А поведенческий (способы поведения в конфликтной ситуации) и когнитивный (адаптивность в ситуациях общения) компоненты, в свою очередь, обеспечивают защищенность личности.

Изучая эмоциональный компонент, мы взяли за основу параметр выраженности социальных качеств личности и исследовали их особенности с помощью методики «Семь качеств личности» Р. Кеттелла (модификация А.Г. Грецова). При выявлении сформированности когнитивного компонента исследовалось сразу два его аспекта: самооценка и уровень притязаний, а также адаптивность в ситуациях общения. При этом применялись такие методики, как «Диагностика самооценки и уровня притязаний Дембо-Рубинштейн» (модификация А.М. Прихожан) и «Изучение способности к самоуправлению в общении». Для определения развития поведенческого компонента нами использовалась методика «Тест описания поведения К. Томаса (адаптация Н.В. Гришиной)» В целях выявления доминирующих типов поведения.

Можно выделить три уровня развития социального интеллекта в соответствии с его компонентами. Как утверждает Е.А. Зайцева [5], уровням его развития соответствуют следующие характеристики:

1. высокий уровень - ребенок знаком с правилами поведения в обществе и соблюдает их, способен давать адекватную оценку поведению (своему и окружающих) в рамках социального контекста, готов к предвидению своих действий; правильно оценивает себя, формирует сбалансированное и точное представление о себе; умеет слушать собеседника, готов к коллективному взаимодействию, умеет объяснять и убеждать других, легко налаживает контакт со взрослыми и сверстниками; стремится проявлять эмоциональный контроль, старается преодолевать коммуникативный и моральный эгоцентризм, эмоциональный отклик соответствует социальному контексту;

2. средний уровень - знаком и чаще всего соблюдает правила поведения в обществе, дает общую оценку поведению (своему и окружающих) в рамках социального контекста, но не всегда осознает последствия своих действий; обладает недостаточно адекватной самооценкой, но знает свои слабые стороны и стремится к самосовершенствованию; не всегда слушает собеседника, принимает роли, диктуемые ситуацией, объясняет свои действия, но не всегда может убеждать других, контакт со взрослыми и сверстниками вступает с осторожностью; практически не стремится проявлять эмоциональный контроль, не старается преодолевать коммуникативный и моральный эгоцентризм, эмоциональный отклик не всегда соответствует социальному контексту;

3. низкий уровень - имеет общее представление о правилах поведения, но не проецирует эти правила на себя, уклоняется от оценки поведения своего и окружающих, задумывается о возможных последствиях только по предложению взрослого; приписывает себе несуществующие недостатки/ достоинства и переоценивает их в сторону занижения или завышения соответственно; прислушивается преимущественно к взрослому: пассивно принимает и исполняет роли в ситуации коллективного взаимодействия, в итоге затрудняется в выстраивании взаимоотношений с окружающими; не стремится проявлять эмоциональный контроль, в большинстве случаев превалирует коммуникативный и моральный эгоцентризм, эмоциональный отклик не всегда соответствует социальному контексту [2].

Эмпирическая часть исследования была проведена на базе ГОУ ТО «Барсуковская школа им. А.М. Гаранина» (г. Тула). В нем приняли участие подростки с диагнозом «умственная отсталость». Его результаты показали низкую сформированность социального интеллекта по всем трем компонентам. В ходе изучения особенностей когнитивного компонента мы основывались на двух его аспектах: адаптивности в общении и самооценке. Выявлено, что для каждого испытуемого характерна потребность проявлять в зависимости от ситуации направленность на партнера, недостаточная готовность к диалогу, неумение изменять стиль общения в зависимости от ситуации, отсутствие мобильности в общении. Также, среди данного контингента испытуемых распространен неадекватно завышенный уровень притязаний, не являющийся стимулом для дальнейшего развития. Из этого 
следует вывод: когнитивный компонент социального интеллекта развит у подростков с умственной отсталостью недостаточно.

В результате исследования эмоционального компонента выявлено, что у данной категории детей преобладает высокий уровень общительности, характерна чрезмерная открытость. У них наблюдается невосприимчивость к переживаниям окружающих. Не характерны яркие проявления рассудительности или импульсивности. Подростки с умственной отсталостью зачастую излишне доверчивы в ситуациях общения. Кроме того, этим детям свойственен низкий уровень тревожности, в ситуациях общения безразличие носит выраженный характер. Данный компонент социального интеллекта у данной категории детей так же, как и предыдущий, развит слабо.

В ходе изучения поведенческого компонента мы выявили, что в конфликтах обследуемые зачастую приносят в жертву собственные интересы ради другого или вовсе не стремятся ни к кооперации, ни к достижению собственных целей. Это свидетельствует о слабом развитии поведенческого компонента социального интеллекта у подростков с умственной отсталостью.

Таким образом, проведенное нами исследование показало, что для подростков с умственной отсталостью характерно отсутствие адаптивности в ситуации общения, некритически завышенная самооценка, недостаточная сформированность социальных качеств и в большинстве случаев неумение применять продуктивные типы поведения в конфликтных ситуациях. Соответственно, для данной категории детей необходимо организовать коррекционно-развивающую работу по развитию когнитивного, поведенческого и эмоционального компонентов.

Опыт психолого-педагогического изучения детей с умственной отсталостью в качестве субъекта социального познания имеет относительно короткую историю. Стоит также отметить слабую степень разработанности проблемы взаимосвязи социального интеллекта и личностной безопасности.

Однако, многие аспекты проблемы успешности межличностного познания детей с нарушениями интеллекта в ряде исследований были затронуты. Причем в основном все они свидетельствуют об общей недостаточности данного явления.

Так, Егорова О.Н. выявила, что умственно отсталым подросткам затруднительно понимать язык телодвижений, взглядов и жестов. Они не могут участвовать в отборе значимой информации о людях, формировать оценочные суждения о происходящих событиях, пред- видеть последствия действий и поступков. Кроме того, они не способны выражать свои мысли и чувства адекватно ситуации. Эти особенности заметно усложняют взаимоотношения с окружающими и снижают возможности социальной адаптации [4]. Можно предположить, что это негативно сказывается и на их личностной безопасности.

Неумение умственно отсталыми детьми передавать характер взаимоотношений между персонажами, их чувства, переживания при достаточно адекватном понимании своей роли были выявлены благодаря исследованиям Маховой В.М. В случае, если в стимульной ситуации отсутствует прямое указание на причину определяемого эмоционального состояния, умственно отсталые школьники либо опираются на несуществующие детали картины, либо выделяют причину, знакомую им из жизненного опыта, но не адекватную изображенной ситуации [9]. Это в большей степени отрицательно влияет на защищенность личности.

В рамках изучения проблемы развития социального интеллекта у детей с умственной отсталостью также необходимо упомянуть данные исследования Тимофеевой Ж.А., которой установлено, что наличие мотивации к общению, знание ребенком лексики и грамматических конструкций, используемых в диалоге, не обеспечивают ребенку с нарушениями интеллектуального развития полной результативности общения, то есть извлечения всей информации, предоставленной собеседником. Стоит сделать акцент на том, что при этом нарушается и целостность личности ребенка. Причина, по мнению автора, состоит в том, что у детей с нарушениями интеллекта несформированными являются собственно коммуникативная деятельность, умение ребенка выставлять себе задачу на получение информации, находить самостоятельно средства достижения цели и рефлексировать на результат общения [4].

Таким образом, анализ эмпирических исследований свидетельствует о том, что социальный интеллект, обеспечивающий подросткам переработку информации, необходимую для прогнозирования результатов их деятельности, находится на низком уровне. Недостаточно сформированной является и личностная безопасность ребенка.

Идея о необходимости коррекции социального интеллекта детей с нарушениями интеллектуального развития содержится в работе Дж. Лауве [8]. Для развития социальных навыков данной категории детей, по мнению исследователя, следует использовать структурированный и детально разработанный подход. Основу его составляет формирование умения самостоятельно мыслить, а также решать свои проблемы по следующему алгоритму: анализирование проблемы, поиск возмож- 
ных вариантов выхода, определение подходящего типа поведения, возможных последствия своего решения.

Иной подход к коррекции социального интеллекта у подростков с интеллектуальной недостаточностью предлагает Фатихова Л.Ф. Автор считает, что наиболее эффективным и приемлемым подходом является активное использование компьютерных технологий в психокоррекционном процессе, а именно: компьютерных игр, направленных на развитие таких компонентов социального познания, как внутриличностный и межличностный эмоциональный интеллект, способность понимать поступки других людей, прогнозировать их последствия и др. [11].

Многие другие специалисты также опираются на принцип наглядности, используя мультимедийные технологии в своей работе. Зачастую в коррекционно-развивающих программах встречается добавление элементов фильмотерапии, включение упражнений в виде анализа видеосюжетов. Такой способ реализации коррекционного процесса позволяет достичь более высоких результатов.

Результатом проведения нами обследования с помощью диагностической программы и теоретического анализа эмпирических исследований является обоснование и составление коррекционно-развивающей программы с учетом приемлемых на практике подходов.

Так, целью разработанной нами коррекционно-развивающей программы явилось развитие социального интеллекта в соответствии с тремя его компонентами (эмоциональный, когнитивный, поведенческий) у подростков с умственной отсталостью для обеспечения их личностной безопасности.

Коррекционно-развивающая программа составлена в соответствии с требованиями АООП для обучающихся с умственной отсталостью (интеллектуальными нарушениями).

Она включает в себя три блока, направленных на развитие когнитивного, поведенческого и эмоционального компонентов, что предположительно обеспечит формирование целостности и защищенности личности.

В каждом занятии мы выделяли следующие смысловые блоки:

1. вводная часть включала в себя организационный момент, приветствие; в некоторых занятиях проводилась рефлексия прошлого занятия с целью закрепления полученного опыта;

2. основная часть состояла из совокупности психологических упражнений и теоретического материала, подобранных в соответствии с задачами занятия, в каждом занятии просматривался видеофрагмент для наглядного представления;

3. заключительная часть занятия завершалась обсуждением в группе итогов занятия (рефлексивный анализ в форме беседы), релаксацией и прощанием.

В коррекционную программу вошли игры и упражнения, разработанные Р.Р. Калининой [7], А.А. Хлебтуновой [12] и Э. Эмир-Аметовой [13], которые были нами адаптированы с учетом личностных, интеллектуальных и возрастных особенностей подростков с умственной отсталостью. Актуальность составления данной коррекционно-развивающей программы обусловлена отсутствием таковой с учетом этого возраста и нарушения.

В занятиях поэтапно задействованы упражнения на развитие компонентов социального интеллекта. Также, использованы видеофрагменты, демонстрирующие ситуации общения и закрепляющие эффективные способы поведения в них. Полученные на занятиях знания обсуждались в ходе рефлексивной беседы на доступном для подростков уровне.

Таким образом, предложенная коррекционно-развивающая программа предусмотрена для работы с подростками с легкой и умеренной степенью умственной отсталости. Опираясь на общие принципы психокоррекции и индивидуальные особенности данной группы детей, мы составили доступную, но в то же время эффективно влияющую на все компоненты социального интеллекта программу.

Программа содержит многофункциональные упражнения, оказывающие различное воздействие на социальный интеллект подростка: анализ видеофрагментов, проигрывание проблемных ситуаций, упражнения на развития невербальных средств общения, сюжетно-ролевые игры. На протяжении всех занятий активно используются такие методы, как беседа и наблюдение.

Важно отметить, что психолого-педагогическая деятельность, направленная на повышение социального интеллекта дополнительно может осуществляться в следующих направлениях:

1. Просветительская деятельность в виде организации лекций, создание информационных стендов, разработка буклетов и памяток, направленная на повышение психологической грамотности, формирование основ безопасного поведения в коммуникативных ситуациях.

2. Профилактическая деятельность, направленная на предупреждение возможных рисков, связанных с ситуациями межличностного общения подростков с умственной отсталостью; может осуществляться в рамках семинаров, решения 
кейсов, дискуссий и круглых столов.

3. Выполнение заданий, упражнений, направленных на осознанное и произвольное использование вербальных и невербальных средств коммуникации.

4. Рассмотрение в процессе работы проблемных ситуаций, актуальных для подростков, которые могут способствовать развитию способности к пониманию мотивов другого человека и способности прогнозировать поведение другого человека.

Развитие способности понимать невербальные сигналы целесообразно организовывать в виде занятий с элементами тренинга, в которые будут входить упражнения, направленные на распознавание эмоционального состояния другого человека через невербальные сигналы, и корректная передача собственного состояния. Кроме того, будут уместны формы работы, предусматривающие активное взаимодействие участников между собой. Развитие способности прогнозировать поведение другого человека можно производить через методы ролевой и деловой игр, что поможет расширить жизненный опыт участников через моделирование ситуаций.
Также, будет полезно групповое обсуждение актуальных затруднительных случаев из жизни участников. Развитие способности понимать мотивы поведения другого человека возможно посредством беседы, анализа ситуаций, обсуждения случаев из жизни, книг, видеосюжетов. Кроме того, при развитии социального осознания большое значение имеет рефлексивность. Данные приемы включены в составленную нами коррекционно-развивающую программу.

Таким образом, предполагаемый результат включает со стороны подростков с интеллектуальной недостаточностью развитие способности к общению на основе взаимного уважения, способности дифференцировать свои эмоциональные состояния и распознавать эмоциональные состояния окружающих, умения регулировать эмоциональное состояние и контролировать свое поведение, а также повышение коммуникативной активности и сформированность основ общекультурных навыков поведения. По нашему мнению, совокупность перечисленных способностей в дальнейшем обеспечит повышение уровня личностной безопасности.

\section{ЛИТЕРАТУРА}

1. Баширов И.Ф. Социальный интеллект как фактор успешности профессиональной деятельности военного психолога. - Москва, 2006. - 210 с.

2. Волкова Т. Виктимологическая профилактика: Требуется обучение населения правилам безопасного поведения // Российская юстиция. - $2009 .-178$ c.

3. Демьяненок Т.В. Психолого-педагогическое сопровождение детей с тяжелым нарушением интеллекта в процессе их социально-бытовой адаптации // Интегративные тенденции современного специального образования. Сб. тез. Межд. науч-прак. Конф. Минск, 2003. С. 197-201.

4. Егорова 0.Н. Особенности социального интеллекта подростков с легкой степенью умственной отсталости с девиантным поведением // Современные проблемы науки и образования. - 2014. - № 1. URL: http://science-education.ru/ru/article/view?id=12209 (дата обращения: 03.11.2021)

5. Зайцева Е.А. К вопросу о развитии социального интеллекта в учебной деятельности младших школьников // Современные проблемы науки и образования. -2015 . - № 1.

6. Исаев Д.Н. Наиболее важные направления в изучении проблемы умственной отсталости // Вестник Санкт-Петербургского Университета / Ред. Н.М. Кропачев, И.А. Горлинский, Н.Г. Скворцов. - 2009. - № 4- с.236-240.

7. Калинина Р.Р. Тренинг развития личности дошкольника: занятия, игры, упражнения.- СПб.; «РЕЧь», 2002. - 74 с.

8. Лауве Дж. Пути интеграции. Учебный план в помощь социально-эмоциональному развитию детей с особыми нуждами //Дефектология, 1994, № 6.- С. 76-81.

9. Махова В.М. Изучение личностных свойств и особенностей эмоционального реагирования детей с интеллектуальной недостаточностью в период их адаптации к школе // Дефектология, 2000, №6 .- С. 24-35.

10. Приходько 0.Г., Кондрашова А.А. Социальное развитие детей с ограниченными возможностями здоровья // Специальное образование. 2014. №3. URL: https://cyberleninka.ru/article/n/sotsialnoe-razvitie-detey-s-ogranichennymi-vozmozhnostyami-zdorovya (дата обращения: 01.11.2021)

11. Фатихова Л.Ф. Социальный и эмоциональный интеллект детей с интеллектуальными нарушениями: подходы к изучению и коррекции. - Уфа: РИЦ. БашГУ, 2017. - 140 c.

12. Хлебтунова А.А. Психологическая коррекция эмоциональной сферы подростков с интеллектуальными нарушениями. СПб.: Речь, 2010. - 65 с.

13. Эмир-Аметова Э. Развитие социального интеллекта у воспитанников детских домов. Балашов: Изд-во «Николаев», 2007. - 76 с.

(c) Степанова Наталия Анатольевна (stepanova_na@inbox.ru), Максимова Дарья Алексеевна (darmaximova@mail.ru). 